Energy may be defined as work which is stored up. Work stored up in overcoming kinetic reactions is called kinetic energy. Work stored up in overcoming non-frictional forces, such as gravitational forces, is called potential energy. Work done in overcoming frictional forces is called heat energy.

Potential, kinetic and heat energy are different (at least apparently ${ }^{2}$ ) forms of the same physical entity, $i$. e., energy. Energy may be changed from any one of these forms into any other form. Whenever such a change takes place energy is said to be transformed. Transformation of energy is always accompanied by work. In fact the process of doing work is that of transformation of energy. The amount of energy transformed equals the amount of work done.3

YALE UNIVERSITY

\section{UNITS OF FORCE}

To the Editor of ScIEnce: I have read with much interest Professor Kent's article in ScIENCE on the units of force. I might say that $I$ have taught mechanics in my physics course this year, using the units the way Professor Kent recommends. The results have been entirely successful and highly gratifying. I used the pound and the gram as the units of mass and the pound and the gram as the units of force. As far as the results to the student go it has resulted in conciseness and clearness of thought and an avoidance of the unescapable confusion that results from introducing units that nobody but a teacher of physics wishes to use. Not only did this apply to force equations but it had a good result all along the line in problems on work energy and power. I embodied in my method of teaching the things that Professor Kent recommends and also many of the things that Professor Huntington recommends. I believe that a great deal of the trouble is due to the fact that most of our teachers of physics do not have the point of view of the engineer (they should have if they teach engineers) and

2 Recent developments in physical sciences tend to show that differences between different forms of energy are only apparent and that all forms of energy are, in the last analysis, kinetic.

3 H. M. Dadourian, "Analytical Mechanics," 2 d edition, p. 248.

H. M. Dadourian
I believe that the only way to get this point of view is in the school of practical engineering. This hodgepodge of units which some of us wish to use are undesirable and pedagogically unsound.

\section{Paul Cloke}

\section{THERMOMETER SCALES}

To the Editor of Science: In a letter published in Science of May 5, 1916, page 642, a correspondent advocating the retention of the Fahrenheit scale says that "nine tenths, probably, of the use of the thermometer is for the weather" a statement that should not pass unchallenged; but even if there were no other uses of the thermometer, the Fahrenheit scale would still be objectionable. If your correspondent will visit any extensive meteorological library, he will find that nearly all national weather services now use the Centigrade scale and that internationally no other scale has been recognized for some years. Even the few weather services retaining the Fahrenheit scale, restrict its use and banish it from all investigational and research work.

It is urged that "the common people are familiar with the Fahrenheit scale." They may be familiar with it and yet not understand it. When the temperature is $64^{\circ} \mathrm{F}$., is it clearly understood by every one, that the temperature is 32 degrees above freezing; and on the other hand when it is $-32^{\circ} \mathrm{F}$., that the temperature is 64 degrees below freezing? The scale says one thing and means another. It is true that the Centigrade scale dive sion is nearly twice the length of the other scale division; and much has been made of this by some who insist upon accuracy to the tenth of a degree; but it may be well to remember that most air temperatures are a degree or more in error. Even with official instruments, errors of exposure or time, exceeding several degrees, go uncorrected, while instrumental errors are applied to a tenth of a degree. On the daily weather map one finds isotherms charted from readings made at different hours and different elevations. A reading made at $\boldsymbol{5}$ A.M. in the Nevada desert is linked up with readings made at 8 A.M. on the Atlantic seaboard. Some years ago, I suggested to the 